\title{
Expression of ERCC1 and class III $\beta$-tubulin is associated with the survival of resected stage III non-small cell lung cancer patients treated with induction chemoradiotherapy using carboplatin-taxane
}

\author{
CHENG-LONG HUANG ${ }^{1}$, KYUICHI KADOTA ${ }^{1}$, DAGE LIU ${ }^{1}$, MASAKI UENO ${ }^{2}$, NARIYASU NAKASIMA ${ }^{1}$, \\ SHINYA ISHIKAWA ${ }^{1}$, MASASHI GOTOH ${ }^{1}$, NORIYUKI MISAKI ${ }^{1}$, \\ SUNG-SOO CHANG ${ }^{1}$ and HIROYASU YOKOMISE ${ }^{1}$
}

Departments of ${ }^{1}$ General Thoracic Surgery, Breast and Endocrinological Surgery, and ${ }^{2}$ Pathology and Host Defense, Faculty of Medicine, Kagawa University, Kagawa 761-0793, Japan

Received January 13, 2010; Accepted March 16, 2010

DOI: $10.3892 /$ etm_00000069

\begin{abstract}
Several molecules have been proven to be associated with responsiveness to chemotherapy. A clinical study on the expression of excision repair cross-complementing (ERCC)-1 and class III $\beta$-tubulin was conducted in advanced stage non-small cell lung cancer (NSCLC) patients. We investigated 34 resected stage III NSCLC patients treated with induction chemoradiotherapy using carboplatin-taxane. Immunohistochemistry was performed to evaluate the intratumoral expression of ERCC1 and class III $\beta$-tubulin. Nineteen tumors (55.9\%) were ERCC1-high and 11 (32.4\%) were class III $\beta$-tubulin-high. There was no correlation between ERCC 1 and class III $\beta$-tubulin expression $(\mathrm{r}=0.208)$. Regarding the pathological effect of induction therapy, the percentage of ERCC1-positive tumor cells was lower in tumors with a major response than in tumors with a minor response $(\mathrm{P}=0.0851)$. The percentage of class III $\beta$-tubulin-positive tumor cells was significantly lower in tumors with a major response than in tumors with a minor response $(\mathrm{P}=0.0105)$. Regarding patient survival, the overall survival was significantly higher in patients with ERCC1-low tumors than in those with ERCC1-high tumors $(\mathrm{P}=0.0034)$. The overall survival was also significantly higher in patients with class III $\beta$-tubulin-low tumors than in those with class III $\beta$-tubulin-high tumors $(\mathrm{P}=0.0185)$. Cox regression analysis also demonstrated that ERCC1 $(\mathrm{P}=0.0467)$ and class III $\beta$-tubulin statuses $(\mathrm{P}=0.0237)$ were significant
\end{abstract}

Correspondence to: Dr Cheng-Long Huang, Department of General Thoracic Surgery, Breast and Endocrinological Surgery, Faculty of Medicine, Kagawa University, 1750-1 Ikenobe, Miki-cho, Kita-gun, Kagawa 761-0793, Japan

E-mail: chuang@kms.ac.jp

Key words: excision repair cross-complementing, carboplatin, class III $\beta$-tubulin, taxane, chemotherapy, lung cancer prognostic factors. Co-evaluations of the intratumoral expression of ERCC 1 and class III $\beta$-tubulin are clinically useful for identifying patient populations responsive to chemotherapy using carboplatin-taxane.

\section{Introduction}

Non-small cell lung cancer (NSCLC) is one of the most common human cancers associated with a poor patient prognosis. Although previous studies have shown that chemotherapy improves patient survival in completely resected NSCLC (1,2), only an additional 5-15\% of treated individuals ultimately benefit with improvement in their long-term interval (3). On the other hand, recent molecular biology studies have revealed that many molecules affect the various biological behaviors of malignant tumors (4). Several molecules have been proven to be associated with the responsiveness to chemotherapy, and the selection of an effective chemotherapy based on an evaluation of these molecules, namely 'tailor-made chemotherapy', may improve the clinical outcome of NSCLC patients $(5,6)$. In fact, epidermal growth factor receptor (EGFR)-specific tyrosine kinase inhibitors, such as gefitinib and erlotinib, have been proven to be effective for NSCLCs with EGFR gene mutations (7). In addition, 5-fluorouracil (5-FU)-derived agents, such as S-1 and UFT, are effective for NSCLCs with a low expression of thymidylate synthase (TS) (8). At present, we are utilizing tailor-made chemotherapy based on the co-evaluation of EGFR mutations and TS expression for NSCLC patients.

However, most NSCLCs with EGFR mutations or low TS expression are adenocarcinomas. The remaining populations of NSCLCs require chemotherapy using other drugs based on the evaluation of other targeted molecules. Other anti-tumor agents are considered based on evaluations of other chemotherapy-associated molecules. For example, the intratumoral expression of excision repair crosscomplementing (ERCC)-1, a leading component of nucleotide excision repair (NER), is associated with the responsiveness 
to platinum-based chemotherapy, such as cisplatin and carboplatin (9-12). In addition, the intratumoral expression of class III $\beta$-tubulin is associated with the responsiveness to taxanes, such as paclitaxel and docetaxel (13-15). Therefore, a clinical study on the expression of ERCC1 and class III $\beta$-tubulin was conducted in resected advanced stage NSCLC patients treated with induction chemoradiotherapy using carboplatin-taxane, in order to more widely establish the treatment strategy of tailor-made chemotherapy.

\section{Materials and methods}

Clinical characteristics of the patients. From January 2000 to April 2006, 41 patients with bulky-cN2, N3 stage III NSCLC underwent surgery after induction chemoradiotherapy at the Department of General Thoracic Surgery, Breast and Endocrinological Surgery, Faculty of Medicine, Kagawa University, as reported previously (16). This study was approved by the Institutional Review Board of Kagawa University (14-7, a clinical study of biological markers in nonsmall cell lung cancers). Signed, written informed consent was obtained from all patients before therapy was initiated. Patient clinical records and histopathological diagnoses were fully documented.

The therapeutic schedule for induction chemoradiotherapy was performed as follows (16): chemotherapy was conducted during week 1, and concurrent radiotherapy with 30 Gy was conducted during weeks 1, 2 and 3. After a 1-week withdrawal period, chemotherapy was carried out during week 5, and concurrent radiotherapy with 20 Gy was carried out during weeks 5 and 6 . The therapies were discontinued for 1-4 weeks depending on the condition of the patient, and a re-evaluation was carried out using chest CT, abdominal CT, brain CT or magnetic resonance imaging and bone scan. A routine re-evaluation of induction chemoradiotherapy was carried out according to the 'New guidelines to evaluate the response to treatment in solid tumors' (17). A complete resolution of all targets was defined as complete response and at least a $30 \%$ reduction (quantified as the longest diameter) in the tumor size was defined as partial response. After the re-evaluation of induction chemoradiotherapy, complete surgical resections were performed for all patients.

Regarding chemotherapy, the patients were randomly assigned to a carboplatin-paclitaxel (CP) arm and a carboplatin-docetaxel (CD) arm (16). Patients in the CP arm received carboplatin (area under the curve $6 \mathrm{mg} /(\mathrm{ml}, \mathrm{min})$, $30-\mathrm{min}$ intravenous infusion) and paclitaxel $\left(180 \mathrm{mg} / \mathrm{m}^{2}, 3-\mathrm{h}\right.$ intravenous infusion) on day 1 . The patients in the $\mathrm{CD}$ arm received carboplatin (area under the curve $6 \mathrm{mg} /(\mathrm{ml}, \mathrm{min})$, 30 -min intravenous infusion) and docetaxel $\left(60 \mathrm{mg} / \mathrm{m}^{2}, 3-\mathrm{h}\right.$ intravenous infusion) on day 1 . Regarding radiotherapy, an area including the hilum of the lung and mediastinum with a $1.5-\mathrm{cm}$ margin from the periphery of the primary lesion was irradiated with $2 \mathrm{~Gy} /$ day. The patients received irradiation five times weekly, with 2 non-irradiation days set up.

The pathological effect of induction therapy was evaluated according the General Rules for Clinical and Pathological Record of Lung Cancer, 6th edition (18); a pathologically complete response (complete cancer cell death), a major response (fewer than one-third of cancer cells viable) and a
Table I. Patient characteristics.

\begin{tabular}{|c|c|c|}
\hline Characteristics & No. of patients & Percentage \\
\hline Total no. of patients & 34 & 100 \\
\hline \multicolumn{3}{|l|}{ Age } \\
\hline Median & 63.5 & \\
\hline Range & $46-75$ & \\
\hline \multicolumn{3}{|l|}{ Gender } \\
\hline Male & 28 & 82.4 \\
\hline Female & 6 & 17.6 \\
\hline \multicolumn{3}{|l|}{ Histology } \\
\hline Adenocarcinoma & 19 & 55.9 \\
\hline Squamous cell carcinoma & 15 & 44.1 \\
\hline \multicolumn{3}{|l|}{ Pathological stage } \\
\hline Stage IIIA & 24 & 70.6 \\
\hline T1N2M0 & 8 & 23.5 \\
\hline T2N2M0 & 15 & 44.1 \\
\hline T3N2M0 & 1 & 2.9 \\
\hline Stage IIIB & 10 & 29.4 \\
\hline $\mathrm{T} 2 \mathrm{~N} 3 \mathrm{M} 0$ & 3 & 8.8 \\
\hline T4N2M0 & 6 & 17.6 \\
\hline T4N3M0 & 1 & 2.9 \\
\hline \multicolumn{3}{|l|}{ Chemotherapy } \\
\hline Carboplatin plus paclitaxel & 15 & 44.1 \\
\hline Carboplatin plus docetaxel & 19 & 55.9 \\
\hline Radiotherapy & 34 & 100 \\
\hline \multicolumn{3}{|l|}{ Method of surgical resection } \\
\hline Lobectomy or bilobectomy & 24 & 70.6 \\
\hline Pneumonectomy & 10 & 29.4 \\
\hline \multicolumn{3}{|l|}{ Response to induction therapy } \\
\hline Partial response & 24 & 70.6 \\
\hline Stable disease & 10 & 29.4 \\
\hline \multicolumn{3}{|l|}{$\begin{array}{l}\text { Pathological effect of } \\
\text { induction therapy }\end{array}$} \\
\hline Major response & 23 & 67.6 \\
\hline Minor response & 11 & 32.4 \\
\hline
\end{tabular}

minor response (more than one-third of cancer cells viable). Among them, 7 patients with a pathologically complete response were excluded, since immunohistochemical evaluations using surgically resected tumor specimens were not possible. Finally, 34 patients with stage III NSCLC were investigated as shown in Table I. They included 19 adenocarcinomas and 15 squamous cell carcinomas. Regarding chemotherapy, 15 patients received the CP arm and 19 patients received the $\mathrm{CD}$ arm. Regarding surgical method, a lobectomy or bilobectomy was performed in 24 patients, and a pneumonectomy was performed in 10 patients.

Immunohistochemistry. A mouse monoclonal antibody for ERCC1 (8F1; Santa Cruz Biotechnology Inc., Santa Cruz, CA, USA) diluted at 1:300 and a mouse monoclonal antibody for 
A

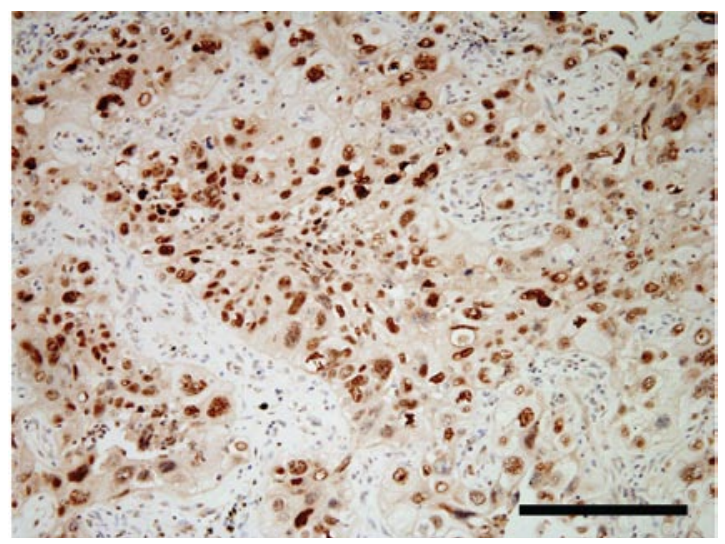

C

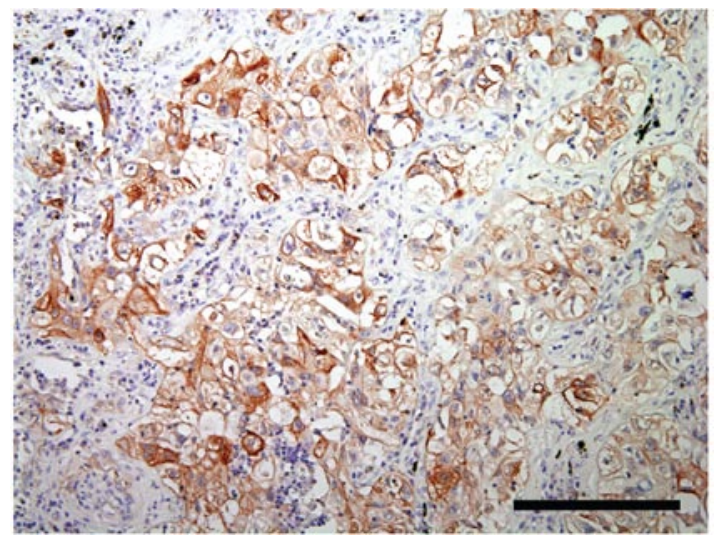

B

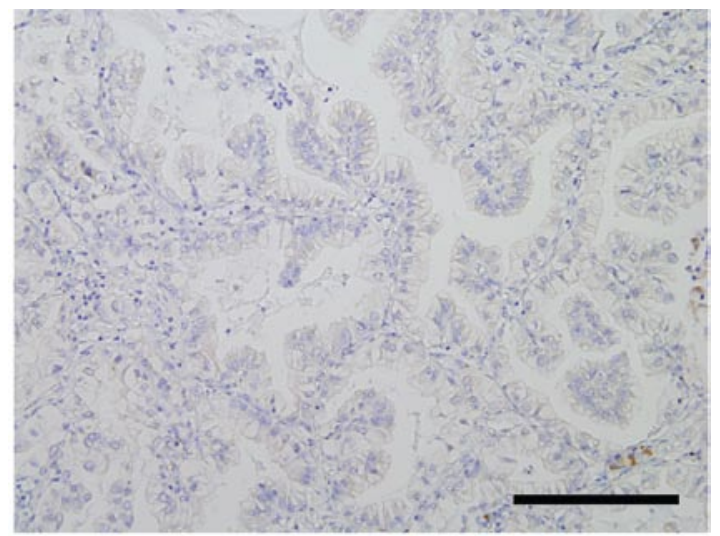

D

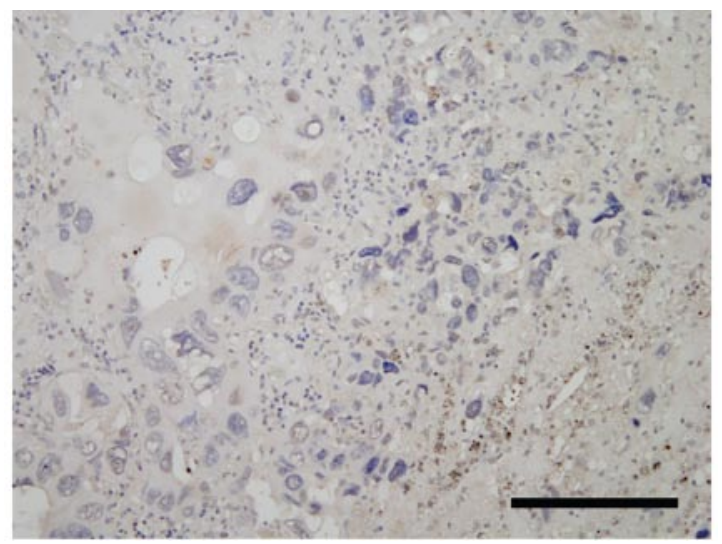

Figure 1. Immunohistochemical staining of human non-small cell lung cancer tissues using the avidin-biotin-peroxidase complex procedure. An ERCC-high carcinoma (A), an ERCC1-low carcinoma (B), a class III $\beta$-tubulin-high carcinoma (C) and a class III $\beta$-tubulin-low carcinoma (D). Bar, $50 \mu$ m.

class III $\beta$-tubulin (TU-20; AbD Serotec, Oxford, UK) diluted at 1:3 were used. Formalin-fixed paraffin-embedded tissue was cut into $4-\mu \mathrm{m}$ sections and mounted on poly-L-lysinecoated slides. Sections were deparaffinized and rehydrated. The slides were then heated in a microwave for $10 \mathrm{~min}$ in a $10 \mu \mathrm{mol} / \mathrm{l}$ citrate buffer solution at $\mathrm{pH}$ 6.0. After quenching the endogenous peroxidase activity with $0.3 \% \mathrm{H}_{2} \mathrm{O}_{2}$ (in absolute methanol) for $30 \mathrm{~min}$, the sections were treated for $2 \mathrm{~h}$ with $5 \%$ bovine serum albumin to block non-specific staining. Duplicate sections were incubated overnight with primary antibodies, respectively. Slides were then incubated for $1 \mathrm{~h}$ with biotinylated anti-mouse IgG secondary antibodies (Vector Laboratories Inc., Burlingame, CA, USA). The sections were incubated with the avidin-biotin-peroxidase complex (Vector Laboratories Inc.) for $1 \mathrm{~h}$, and antibody binding was visualized with 3,3'-diaminobenzidine tetrahydrochloride. Lastly, the sections were lightly counterstained with Mayer's hematoxylin. All immunostained sections were independently evaluated by two authors (C.H. and K.K.), without knowledge of the patient characteristics. Five areas were selected at random and scored in cases with multiple areas of low intensity. Also, one random field was selected in sections where all staining appeared intense. At least 200 cells were scored per x40 field about tumor cells.

Statistical analysis. Since the distributions of two values, including the percentages of ERCC1-positive tumor cells $(\mathrm{P}=0.8830)$ and class III $\beta$-tubulin-positive tumor cells $(\mathrm{P}=0.5397)$, showed normal distributions (Kolmogorov-
Smirnov analysis), the statistical significances of ERCC1 or class III $\beta$-tubulin expression in relation to the clinical and pathological parameters were assessed by the t-test or the $\chi^{2}$ test. The sample was classified as an ERCC1-high tumor when $>30 \%$ of the tumor cells had positive staining of ERCC1 because of the greatest significance in relation to patient survival. The sample was also classified as a class III $\beta$-tubulinhigh tumor when $>30 \%$ of tumor cells had positive staining of class III $\beta$-tubulin because of the greatest significance in relation to patient survival. Overall survival was defined as the time from treatment initiation (surgical resection, chemotherapy or radiation) to the date of death from any cause. The Kaplan-Meier method was used to estimate the probability of overall survival as a function of time, and differences in the survival of subgroups of patients were compared by using the Mantel's log-rank test. A multivariate analysis was performed using the Cox regression model to study the effects of different variables on survival. All P-values were based on two-tailed statistical analysis, and a P-value of $<0.05$ was considered to indicate statistical significance.

\section{Results}

ERCC1 expression in NSCLCs. The intratumoral ERCC1 expression exhibited a nuclear staining pattern (Fig. 1A). The percentage of ERCC1-positive tumor cells varied greatly (median 30\%; mean \pm SD, 34.1 $\pm 22.9 \%$ ). Among 34 stage III NSCLCs, 19 tumors (55.9\%) were ERCC1-high (Table IIA). Seven of the 19 adenocarcinomas $(36.8 \%)$ were ERCC1-high 
Table II. ERCC1 and class III $\beta$-tubulin expression in 34 non-small cell lung cancers.

A, ERCC1 expression.

\begin{tabular}{|c|c|c|c|c|c|c|}
\hline \multirow[b]{2}{*}{ Histology } & \multirow[b]{2}{*}{$\mathrm{n}$} & \multicolumn{4}{|c|}{ Percentage of ERCC1-positive cells } & \multirow[b]{2}{*}{ P-value } \\
\hline & & 0 & $1-30$ & $31-50$ & $51-100$ & \\
\hline Adenocarcinoma & 19 & 9 & 3 & 4 & 3 & 0.0119 \\
\hline Squamous cell carcinoma & 15 & 3 & 0 & 5 & 7 & \\
\hline Total & 34 & 12 & 3 & 9 & 10 & \\
\hline
\end{tabular}

B, Class III $\beta$-tubulin expression.

\begin{tabular}{|c|c|c|c|c|c|c|}
\hline \multirow[b]{2}{*}{ Histology } & \multirow[b]{2}{*}{$\mathrm{n}$} & \multicolumn{4}{|c|}{ Percentage of class III $\beta$-tubulin-positive cells } & \multirow[b]{2}{*}{ P-value } \\
\hline & & 0 & $1-30$ & $31-50$ & $51-100$ & \\
\hline Adenocarcinoma & 19 & 8 & 4 & 3 & 4 & 0.4840 \\
\hline Squamous cell carcinoma & 15 & 10 & 1 & 2 & 2 & \\
\hline Total & 34 & 18 & 5 & 5 & 6 & \\
\hline
\end{tabular}

tumors. Twelve of the 15 squamous cell carcinomas $(80.0 \%)$ were ERCC1-high tumors. The percentage of ERCC1-high tumors was significantly higher in the squamous cell carcinomas than in the adenocarcinomas $(\mathrm{P}=0.0119)$. Furthermore, the percentage of ERCC1-positive tumor cells was significantly higher in the squamous cell carcinomas than in the adenocarcinomas $(53.3 \pm 24.8$ vs. $21.3 \pm 17.3 \%, \mathrm{P}=0.0050)$.

Class III $\beta$-tubulin expression in NSCLCs. The intratumoral class III $\beta$-tubulin expression exhibited a cytoplasmic staining pattern (Fig. 1C). The percentage of class III $\beta$-tubulinpositive tumor cells varied greatly (median $0 \%$; mean $\pm \mathrm{SD}$, $15.5 \pm 12.1 \%$ ). Among 34 stage III NSCLCs, 11 tumors $(32.4 \%)$ were class III $\beta$-tubulin-high (Table IIB). Seven of the 19 adenocarcinomas (36.8\%) were class III $\beta$-tubulin-high tumors. Four of the 15 squamous cell carcinomas $(26.7 \%)$ were class III $\beta$-tubulin-high tumors. No significant difference was observed in the percentage of class III $\beta$-tubulin-positive tumor cells between the adenocarcinomas and the squamous cell carcinomas $(18.3 \pm 13.4$ vs. $11.9 \pm 10.4 \%)$.

Relationship between ERCCI and class III $\beta$-tubulin expression in NSCLCs. No correlation was observed between ERCC1 and class III $\beta$-tubulin expression $(\mathrm{r}=0.208, \mathrm{P}=0.2385)$. Among the 34 stage III NSCLCs, 12 tumors (35.3\%) were both ERCC1-low and class III $\beta$-tubulin-low, 11 tumors $(32.4 \%)$ were ERCC1-high but class III $\beta$-tubulin-low, 3 tumors $(8.8 \%)$ were ERCC1-low but class III $\beta$-tubulin-high and 8 tumors (23.5\%) were both ERCC1-high and class III $\beta$-tubulin-high.

Response to induction therapy in relation to ERCC1 or class III $\beta$-tubulin expression in NSCLCs. Regarding the radiological evaluation of response to induction therapy, 24 tumors had a partial response to induction therapy and 10 exhibited stable disease (Table I). Regarding the pathological effect of induc- tion therapy, a major response was observed in 23 patients and a minor response was observed in 11 patients.

Concerning ERCC1 expression, the percentage of ERCC1positive tumor cells was significantly lower in tumors with a partial response than in tumors with stable disease $(26.3 \pm 19.0$ vs. $53.0 \pm 35.6 \%, \mathrm{P}=0.0286$, Fig. $2 \mathrm{~A}$ ). Regarding the pathological effect of induction therapy, a major response was observed in 11 of the 15 ERCC1-low tumors (73.3\%). A major response was observed in 12 of the 19 ERCC1-high tumors (63.2\%). The percentage of ERCC1-positive tumor cells was lower in tumors with a major response than in tumors with a minor response (27.4 \pm 19.1 vs. $48.2 \pm 37.4 \%, \mathrm{P}=0.0851$, Fig. $2 \mathrm{~B})$.

Concerning class III $\beta$-tubulin expression, the percentage of class III $\beta$-tubulin-positive tumor cells was significantly lower in tumors with a partial response than in tumors with stable disease $(8.8 \pm 8.1$ vs. $31.5 \pm 23.3 \%, \mathrm{P}=0.0045$, Fig. $2 \mathrm{C})$. Regarding the pathological effect of induction therapy, a major response was observed in 19 of the 23 class III $\beta$-tubulin-low tumors $(82.6 \%)$. A major response was observed in 4 of the 11 class III $\beta$-tubulin-high tumors (36.4\%). The percentage of class III $\beta$-tubulin-positive tumor cells was significantly lower in tumors with a major response than in tumors with a minor response $(9.0 \pm 8.5$ vs. $29.1 \pm 23.5 \%, P=0.0105$, Fig. $2 \mathrm{D})$.

Overall survival of stage III NSCLC patients treated with carboplatin-taxane in relation to ERCC1 and class III $\beta$-tubulin expression. Regarding ERCC1 expression, the 3-year survival rate was $86.7 \%$ in patients with ERCC1-low tumors and $29.6 \%$ in patients with ERCC1-high tumors (Fig. 3A). The overall survival was significantly higher in patients with ERCC1-low tumors than in those with ERCC1high tumors $(\mathrm{P}=0.0034)$.

Regarding class III $\beta$-tubulin expression, the 3-year survival rate was $65.8 \%$ in patients with class III $\beta$-tubulin-low tumors and $27.3 \%$ in patients with class III $\beta$-tubulin-high 
A

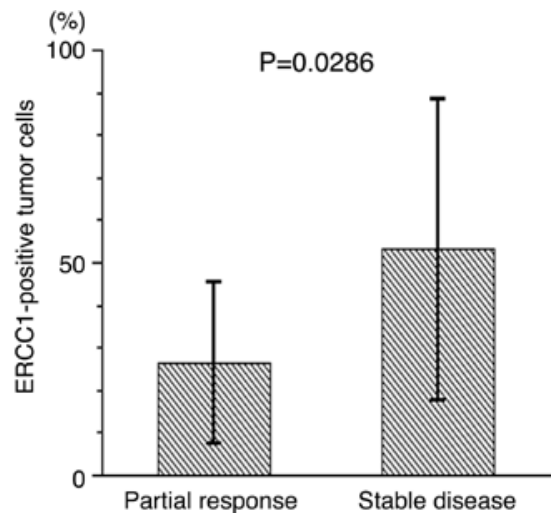

C

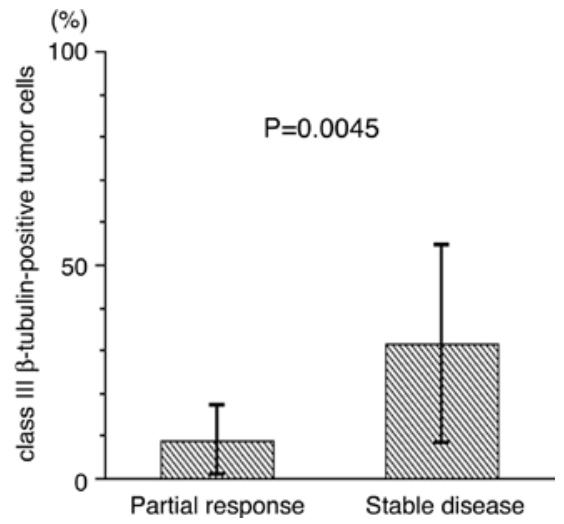

B

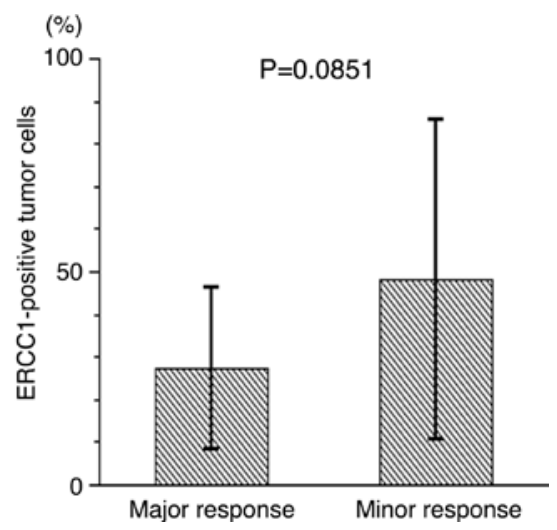

D

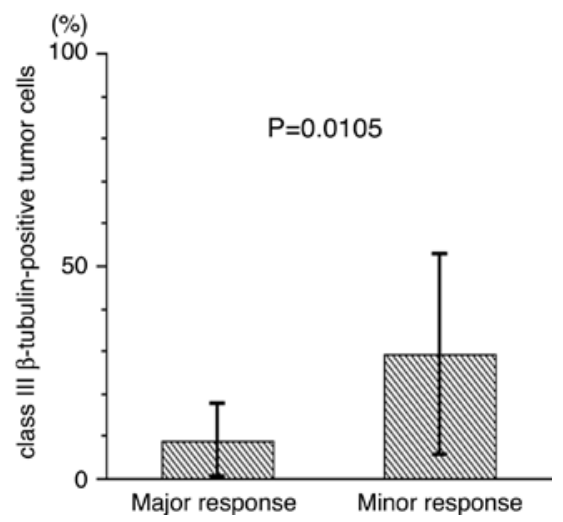

Figure 2. (A) ERCC1 expression according to the response to induction therapy. (B) ERCC1 expression according to the pathological effect of induction therapy. (C) Class III $\beta$-tubulin expression according to the response to induction therapy. (D) Class III $\beta$-tubulin expression according to the pathological effect of induction therapy.
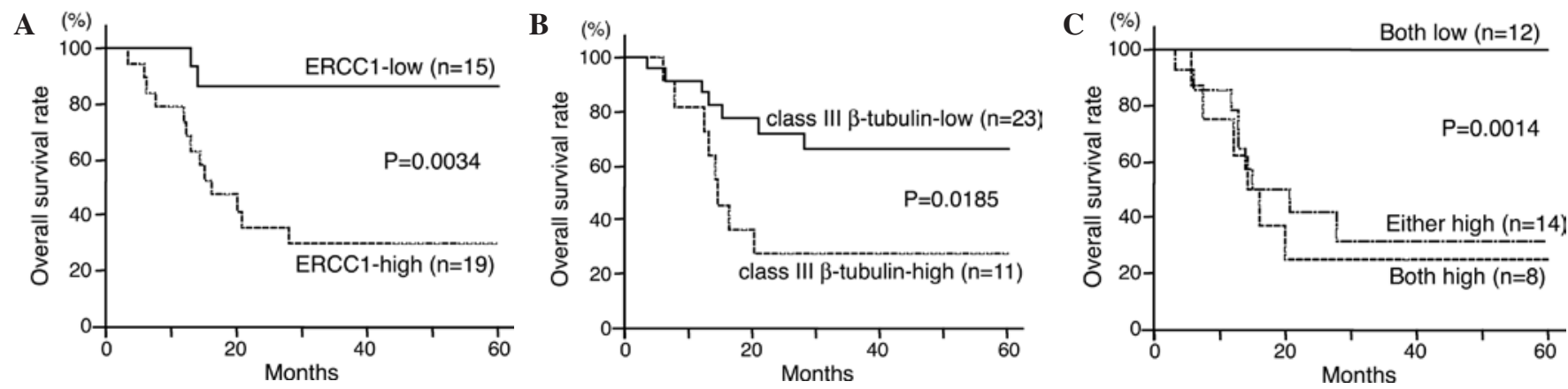

Figure 3. Overall survival of resected stage III non-small cell lung cancer patients with induction chemoradiotherapy using carboplatin-taxane in relation to ERCC1 status (A), in relation to class III $\beta$-tubulin status (B) and in relation to ERCC1 and class III $\beta$-tubulin status (C).

tumors (Fig. 3B). The overall survival was significantly higher in patients with class III $\beta$-tubulin-low tumors than in those with class III $\beta$-tubulin-high tumors ( $\mathrm{P}=0.0185)$.

Regarding expression of ERCC1 and class III $\beta$-tubulin, the 3-year survival rate was $100.0 \%$ in 12 patients with both ERCC1- and class III $\beta$-tubulin-low tumors, $31.2 \%$ in 14 patients with either a ERCC1- or class III $\beta$-tubulin-high tumor and $25.0 \%$ in 8 patients with both ERCC1- and class III $\beta$-tubulin-high tumors (Fig. 3C). The overall survival of the patients with both ERCC1- and class III $\beta$-tubulin-low tumors was significantly the highest among the three groups $(\mathrm{P}=0.0014)$.

A multivariate analyses using the Cox regression model demonstrated that ERCC1 (hazard ratio, 4.686; $\mathrm{P}=0.0467$ ) and the class III $\beta$-tubulin expression levels (hazard ratio, 5.224; $\mathrm{P}=0.0237$ ) were significant prognostic factors for completely resected stage III NSCLC patients treated with induction chemoradiotherapy using carboplatin-taxane (Table III).

\section{Discussion}

Selection of the effective chemotherapy treatment based on the evaluation of tumor-associated molecules, tailor-made chemotherapy, may improve the clinical outcome of NSCLC patients $(5,6)$. At present, we are utilizing tailor-made chemotherapy based on the co-evaluation of EGFR mutations and TS expression for NSCLC patients. NSCLCs with EGFR mutations may be successfully treated with EGFR-specific 
Table III. Multivariate regression analysis in predicting the survival of resected stage III NSCLC patients treated with induction chemoradiotherapy using carboplatin-taxane.

\begin{tabular}{lccr}
\hline Variables & Hazard ratio & $95 \%$ CI & P-value \\
\hline ERCC1 expression & 4.686 & $(1.022-21.475)$ & 0.0467 \\
Class III $\beta$-tubulin expression & 5.224 & $(1.247-21.879)$ & 0.0237 \\
Age ( $\leq 65$ vs. $>65$ years) & 4.253 & $(1.015-17.830)$ & 0.0477 \\
Method of surgical resection & 3.231 & $(0.510-20.479)$ & 0.2132 \\
Chemotherapy (CP vs. CD) & 2.025 & $(0.585-7.006)$ & 0.2653 \\
\hline
\end{tabular}

CI, confidence interval; CP, carboplatin-paclitaxel; CD, carboplatin-docetaxel.

tyrosine kinase inhibitors, such as gefitinib or erlotinib (7). Furthermore, tumors with low expression of thymidylate synthase can be successfully treated with 5-FU-derived agents, such as S-1 and UFT (8). However, most NSCLCs with EGFR mutations or low TS expression are adenocarcinomas, and the remaining populations of NSCLCs require chemotherapy using other drugs based on an evaluation of other targeted molecules. Therefore, the present study on the expression of ERCC1 against carboplatin (9-12) and class III $\beta$-tubulin against taxanes (13-15) in resected advanced stage NSCLC patients treated with carboplatin-taxane was conducted in order to expand the treatment strategy of the tailor-made chemotherapy.

Platinum-based chemotherapy, such as cisplatin and carboplatin, is still the scaffolding of combination chemotherapy in NSCLC patients $(1,2)$. Platinum-based chemotherapy exerts its cytotoxic effect by disrupting the DNA macromolecule, mainly through the formation of intrastrand adducts and interstrand cross-links that could be repaired through the NER pathway (19). The NER pathway involves several steps, and approximately 30 proteins participate in this repair process. Among them, ERCC1 has a crucial role in the incision step, which is the rate-limiting step of the NER pathway. ERCC1 forms a heterodimer with XPF, and the ERCC1/XPF complex is responsible for the incision to cleave the damaged DNA strand. Therefore, functional ERCC1 is considered to play an important role in the repair of cisplatin DNA adducts and in cisplatin sensitivity (11). In fact, previous clinical studies have found a low ERCC1 expression to be associated with a better response to platinum-based chemotherapy and a more favorable survival of cancer patients receiving combination chemotherapy using platinum-based chemotherapy, for NSCLC, gastric cancer and colorectal cancer (9-12). The present study also demonstrated the survival to be significantly higher in patients with ERCC1-low tumors than in patients with ERCC1-high tumors, among resected stage III NSCLC patients treated with induction chemoradiotherapy using carboplatin.

On the other hand, taxanes, including paclitaxel and docetaxel, are also antitumor agents that are widely used for the treatment of NSCLC patients $(20,21)$. Taxanes bind to $\beta$-tubulin, one of the major components of microtubules, and exert their growth-inhibitory effects through the inhibition of microtubule dynamics, resulting in the growth arrest of tumor cells at the G2-M phase (22). There are at least six distinct $\beta$-tubulin isotypes (classes I, II, III, IVa, IVb and VI) in humans (23). Among them, class III $\beta$-tubulin differs from the other tubulin isotypes in its amino acid sequence and post-translational modifications (24). Experimental studies have revealed that the interaction of class III $\beta$-tubulin with taxanes is different from that of other isotypes (25-27). Class III $\beta$-tubulin reduces the polymerization rate of microtubules, thereby overcoming microtubule polymerization by taxanes (28). In fact, high levels of class III $\beta$-tubulin expression have been reported to be associated with resistance to taxanes in many human cancer cell lines, including lung, breast and ovarian cancer $(22,29,30)$. Furthermore, clinical studies have shown class III $\beta$-tubulin overexpression to be associated with resistance to taxanes and the survival of cancer patients treated with taxane-containing chemotherapy (13-15). The present study also demonstrated intratumoral class III $\beta$-tubulin expression to be associated with the response to induction therapy using taxanes. Consequently, in the present study, the survival was significantly higher in patients with class III $\beta$-tubulin-low tumors than in patients with class III $\beta$-tubulin-high tumors.

The present study simultaneously evaluated the intratumoral expression of ERCC1 and class III $\beta$-tubulin to demonstrate that expression of these proteins is independent in advanced stage NSCLCs. In addition, both ERCC1 and class III $\beta$-tubulin expression was associated with survival of patients pre-operatively treated with chemotherapy using carboplatin-taxane. In particular, the 3-year survival rate of patients with ERCC1-low and class III $\beta$-tubulin-low tumors was $100 \%$. Considering these results, the co-evaluations of the intratumoral expression of ERCC1 and class III $\beta$-tubulin are thought to be clinically useful for identifying patient populations that will effectively respond to chemotherapy using carboplatin-taxane. Regarding chemotherapy, no difference was observed in the survival between patients treated with carboplatin-paclitaxel and patients treated with carboplatin-docetaxel, as shown in Table III. In addition, no difference was observed in the patient survival according to the method of surgical resection in the present study, as shown in Table III.

The present study, nevertheless, has several limitations. It was a retrospective study using a relatively small number of patients. Furthermore, the immunohistochemistry was performed using surgically resected tumor tissues after treatment with induction chemoradiotherapy. Therefore, 
the immunohistochemical evaluations in the present study were affected by the induction therapy. In particular, cases with a pathologically complete response (complete cancer cell death) could not be investigated in the present study. A further prospective study should be performed to evaluate the intratumoral expression of these chemotherapy-associated biomarkers using tumor tissues obtained before the initial administration of chemoradiotherapy.

The results from the present and previous studies suggest that platinum-base chemotherapy may be successfully used for tumors with low ERCC1 expression; taxanes for tumors with low class III $\beta$-tubulin expression; EGFR-specific TKIs for tumors with EGFR mutations; 5-FU-derived agents for tumors with low TS expression. In total, the simultaneous evaluation of these four biomarkers enables the selection of effective chemotherapy for approximately $80 \%$ of NSCLC patients (data not shown). Therefore, tailor-made chemotherapy based on the evaluation of biomarkers may improve the clinical outcome of NSCLC patients and decrease treatment toxicity and costs by avoiding the administration of ineffective therapy to patients destined not to benefit.

\section{Acknowledgements}

This study was supported by Grants-in-Aid for Scientific Research from the Japanese Society for Promotion of Science, grant no. 18390379 (C.H.).

\section{References}

1. Arriagada R, Bergman B, Dunant A, et al: Cisplatin-based chemotherapy in patients with completely resected non-small cell lung cancer. N Engl J Med 350: 351-360, 2004.

2. Winton T, Livingston R, Johnson $\mathrm{D}$, et al: Vinorelbine plus cisplatin vs. observation in resected non-small cell lung cancer. N Engl J Med 352: 2589-2597, 2005.

3. Hotta K, Matsuo K, Ueoka H, Kiura K, Tabata M and Tanimoto M: Role of adjuvant chemotherapy in patients with resected non-small cell lung cancer: reappraisal with a metaanalysis of randomized controlled trials. J Clin Oncol 22: 3860-3867, 2004.

4. Huang C, Liu D, Masuya D, Nakashima T, Kameyama K, Ishikawa S, Ueno M, Haba R and Yokomise H: Clinical application of biological markers for treatments of resectable non-small cell lung cancers. Br J Cancer 92: 1231-1239, 2005.

5. Bepler G: Using translational research to tailor the use of chemotherapy in the treatment of NSCLC. Lung Cancer 50: S13-S14, 2005.

6. Huang C, Yokomise H, Fukushima M and Kinoshita M: Tailormade chemotherapy for non-small cell lung cancer patients. Future Oncol 2: 289-299, 2006.

7. Mitsudomi T, Kosaka T, Endoh H, Horio Y, Hida T, Mori S, Hatooka S, Shinoda M, Takahashi T and Yatabe Y: Mutations of the epidermal growth factor receptor gene predict prolonged survival after gefitinib treatment in patients with non-small cell lung cancer with postoperative recurrence. J Clin Oncol 23: 2513-2520, 2005.

8. Nakano J, Huang C, Liu D, Masuya D, Nakashima T, Yokomise H, Ueno M, Wada $\mathrm{H}$ and Fukushima M: Evaluations of biomarkers associated with 5-FU sensitivity for non-small cell lung cancer patients postoperatively treated with UFT. Br J Cancer 95: 607-615, 2006.

9. Lord RV, Brabender J, Gandara D, et al: Low ERCC1 expression correlates with prolonged survival after cisplatin plus gemcitabine chemotherapy in non-small cell lung cancer. Clin Cancer Res 8: 2286-2291, 2002.

10. Olaussen KA, Dunant A, Fouret P, et al: DNA repair by ERCC1 in non-small cell lung cancer and cisplatin-based adjuvant chemotherapy. N Engl J Med 355: 983-991, 2006.
11. Metzger R, Leichman CG, Danenberg KD, et al: ERCC1 mRNA levels complement thymidylate synthase mRNA levels in predicting response and survival for gastric cancer patients receiving combination cisplatin and fluorouracil chemotherapy. J Clin Oncol 16: 309-316, 1998.

12. Shirota Y, Stoehlmacher J, Brabender J, Xiong YP, Uetake H, Danenberg KD, Groshen S, Tsao-Wei DD, Danenberg PV and Lenz HJ: ERCC1 and thymidylate synthase mRNA levels predict survival for colorectal cancer patients receiving combination oxaliplatin and fluorouracil chemotherapy. J Clin Oncol 19: 4298-4304, 2001.

13. Seve P, Mackey J, Isaac S, Tredan O, Souquet PJ, Perol M, Lai R, Voloch A and Dumontet C: Class III $\beta$-tubulin expression in tumor cells predicts response and outcome in patients with non-small cell lung cancer receiving paclitaxel. Mol Cancer Ther 4: 2001-2007, 2005.

14. Mozzetti S, Ferlini C, Concolino P, et al: Class III $\beta$-tubulin overexpression is a prominent mechanism of paclitaxel resistance in ovarian cancer patients. Clin Cancer Res 11: 298-305, 2005.

15. Paradiso A, Mangia A, Chiriatti A, Tommasi S, Zito A, Latorre A, Schittulli F and Lorusso V: Biomarkers predictive for clinical efficacy of taxol-based chemotherapy in advanced breast cancer. Ann Oncol 16 (Suppl 4): 14-19, 2005.

16. Yokomise $\mathrm{H}$, Gotoh $\mathrm{M}$, Okamoto $\mathrm{T}$, Yamamoto $\mathrm{Y}$, Ishikawa $\mathrm{S}$, Nakashima T, Masuya D, Liu D and Huang CL: Induction chemoradiotherapy (carboplatin-taxane and concurrent 50-Gy radiation) for bulky cN2,N3 non-small cell lung cancer. J Thorac Cardiovasc Surg 133: 1179-1185, 2007

17. Therasse P, Arbuck SG, Eisenhauer EA, et al: New guidelines to evaluate the response to treatment in solid tumors. European Organization for Research and Treatment of Cancer. National Cancer Institute of the United States, National Cancer Institute of Canada. J Natl Cancer Inst 92: 205-216, 2000.

18. The Japanese Lung Cancer Society: Rule for Clinical and Pathological Record of Lung Cancer. 6th edition. Kanehara, Tokyo, pp168-169, 2003.

19. Rosell R, Taron M, Barnadas A, Scagliotti G, Sarries C and Roig B: Nucleotide excision repair pathways involved in cisplatin resistance in non-small cell lung cancer. Cancer Control 10: 297-305, 2003.

20. Rigas JR: Taxane-platinum combinations in advanced non-small cell lung cancer: a review. Oncologist 9: 16-23, 2004.

21. Kelly K, Crowley J, Bunn PA Jr, et al: Randomized phase III trial of paclitaxel plus carboplatin versus vinorelbine plus cisplatin in the treatment of patients with advanced non-small cell lung cancer: a Southwest Oncology Group trial. J Clin Oncol 19: 3210-3218, 2001.

22. Burkhart CA, Kavallaris $M$ and Horwitz SB: The role of $\beta$-tubulin isotypes in resistance to antimitotic drugs. Biochim Biophys Acta 1471: 1-9, 2001.

23. Jordan MA and Wilson L: Microtubules as a target for anticancer drugs. Nat Rev Cancer 4: 253-265, 2004.

24. Katsetos CD, Legido A, Perentes E and Mork SJ: Class III $\beta$-tubulin isotype: a key cytoskeletal protein at the crossroads of developmental neurobiology and tumor neuropathology. J Child Neurol 18: 851-866, 2003.

25. Lu Q and Luduena RF: Removal of $\beta$-III isotype enhances taxol induced microtubule assembly. Cell Struct Funct 18: 173-182, 1993.

26. Kamath K, Wilson L, Cabral F and Jordan MA: $\beta$ III-tubulin induces paclitaxel resistance in association with reduced effects on microtubule dynamic instability. J Biol Chem 280: 12902-12907, 2005.

27. Derry WB, Wilson L, Khan IA, Luduena RF and Jordan MA: Taxol differentially modulates the dynamics of microtubules assembled from unfractionated and purified $\beta$-tubulin isotypes. Biochemistry 36: 3554-3562, 1997.

28. Hari M, Yang H, Zeng C, Canizales M and Cabral F: Expression of class III $\beta$-tubulin reduces microtubule assembly and confers resistance to paclitaxel. Cell Motil Cytoskeleton 56: 45-56, 2003.

29. Kavallaris M, Kuo DY, Burkhart CA, Regl DL, Norris MD, Haber M and Horwitz SB: Taxol-resistant epithelial ovarian tumors are associated with altered expression of specific $\beta$-tubulin isotypes. J Clin Invest 100: 1282-1293, 1997.

30. Ranganathan S, Benetatos CA, Colarusso PJ, Dexter DW and Hudes GR: Altered $\beta$-tubulin isotype expression in paclitaxelresistant human prostate carcinoma cells. $\mathrm{Br} \mathrm{J}$ Cancer 77: 562-566, 1998. 